International Review of Research in Open and Distributed Learning Volume 21, Number 3

September $\mathbf{- 2 0 2 0}$

\title{
The Influence of Successful MOOC Learners' Self- Regulated Learning Strategies, Self-Efficacy, and Task Value on Their Perceived Effectiveness of a Massive Open Online Course
}

Daeyeoul Lee, Sunnie Lee Watson, and William R. Watson

Purdue University

\begin{abstract}
High dropout rates have been an unsolved issue in massive open online courses (MOOCs). As perceived effectiveness predicts learner retention in MOOCs, instructional design factors that affect it have been increasingly examined. However, self-regulated learning, self-efficacy, and task value have been underestimated from the perspective of instructors even though they are important instructional design considerations for MOOCs. This study investigated the influence of self-regulated learning strategies, selfefficacy, and task value on perceived effectiveness of successful MOOC learners. Three hundred fifty-three learners who successfully completed the Mountain 101 MOOC participated in this study by completing a survey through e-mail. The results of stepwise multiple regression analysis showed that perceived effectiveness was significantly predicted by both self-regulated learning strategies and task value. In addition, the results of another stepwise multiple regression analysis showed that meta-cognitive activities after learning, environmental structuring, and time management significantly predicted perceived effectiveness.
\end{abstract}

Keywords: self-regulated learning, self-efficacy, task value, MOOCs, perceived effectiveness 


\section{Introduction}

Although massive open online courses (MOOCs) have potential to broaden educational opportunities, their high dropout rates have been a challenging issue. Only a small proportion of learners who enroll in a MOOC complete their course (Alraimi, Zo, \& Ciganek, 2015). In order to address this, factors that influence MOOC retention have been increasingly explored. Among them, perceived effectiveness has been identified as a vital factor that predicted learner retention rates for MOOCs (Sujatha \& Kavitha, 2018). Due to the important role of perceived effectiveness, researchers have recently examined instructional design factors that positively affect it, including course structure (Jung, Kim, Yoon, Park, \& Oakley, 2019) and interaction with instructors (Hone \& El Said, 2016). However, these factors have been examined mainly from the perspective of instructors. Self-regulated learning (SRL) and learner characteristics such as self-efficacy should also be considered in instructional design for effective online learning (Liaw \& Huang, 2013).

In MOOCs, learners are required to have a greater ability to regulate their own learning because there is a lack of support or guidance from instructors (Hood, Littlejohn, \& Milligan, 2015). In a recent systematic literature review study, it was revealed that MOOC learners commonly use several SRL strategies as well as possess self-efficacy and task value beliefs (Lee, Watson, \& Watson, 2019). Although perceived effectiveness is associated with learning strategies employed by learners in online learning settings (Venkatesh, Croteau, \& Rabah, 2014), empirical evidence of the effects of SRL on perceived effectiveness in MOOC environments is scarce. The results of previous studies on online learning showed that SRL strategies, self-efficacy, and task value are significant predictors of perceived effectiveness, which is a measure of satisfaction with traditional online learning (e.g., Artino, 2007, 2008; Cho \& Cho, 2017). In addition, most studies on SRL in MOOCs have mainly focused on learners who were involved in MOOCs, but did not complete the courses (e.g., Hood et al., 2015; Milligan \& Littlejohn, 2016). Considering that successful MOOC learners' behaviors had significantly positive effects on other MOOC learners' success (Davis, Chen, Jivet, Hauff, \& Houben, 2016), there is a need to explore successful MOOC learners' SRL strategies, self-efficacy, and task value as well as the relationships of these factors with perceived effectiveness. Findings about the relationships will provide new insight on instructional design for MOOCs as well as how to support learners' self-regulatory processes in MOOCs.

The purpose of this study was to investigate the influence of SRL strategies, self-efficacy, and task value on successful MOOC learners' perceived effectiveness of a MOOC.

\section{Literature Review}

\section{Perceived Effectiveness of MOOCs}

Perceived effectiveness generally refers to students' "evaluation of the overall effectiveness of the course" (Peltier, Drago, \& Schibrowsky, 2003, p. 267). It has been widely used in earlier studies on online learning as a measure of satisfaction with online learning environments (Hone \& El Said, 2016). Each of the three aspects of perceived effectiveness defined by Peltier et al. (2003) has been utilized as a measure of students' satisfaction with online courses (e.g., Bolliger \& Halupa, 2012; Kang \& Im, 2013). For example, referral likelihood was used to measure students' satisfaction with online courses in Kang and Im's (2013) study. 
Therefore, in this study, perceived effectiveness has been operationally defined as students' perceptions of the overall effectiveness of the course and their satisfaction with the course.

It is common to consider perceived effectiveness in contexts where it is impractical to measure students' actual learning behaviors (Hone \& El Said, 2016). MOOC researchers have increasingly examined perceived effectiveness, since it is not practical to measure hundreds of thousands of individuals' diverse learning behaviors in MOOCs (e.g., Jung et al., 2019). Findings have shown that perceived effectiveness played a vital role in enhancing MOOC effectiveness by predicting learner retention (Sujatha \& Kavitha, 2018) or mediating the effect of course content on retention in a MOOC (Hone \& El Said, 2016). Therefore, it is essential to explore factors that influence the perceived effectiveness of MOOCs. Findings reported in previous studies showed instructional design components such as course content (Hone \& El Said, 2016), and course structure and transactional interaction between course and student (Jung et al., 2019), as vital factors that positively affect MOOC learners' perceived effectiveness of the course. However, previous studies largely examined factors from the perspective of instructors. According to Liaw and Huang (2013), SRL and learner characteristics such as self-efficacy should also be considered in the design of effective online courses. These aspects were also highlighted during learner characteristics analysis in instructional design models such as Dick and Carey's model (Dick \& Carey, 1978) and the ADDIE model (Peterson, 2003), showing that they are critical instructional design considerations.

\section{Factors Contributing to Perceived Effectiveness}

SRL strategies. According to Zimmerman (2000), SRL is defined as "self-generated thoughts, feelings, and actions that are planned and cyclically adapted to the attainment of personal goals" (p. 14). SRL theorists commonly explain that SRL includes meta-cognition, behavior, and motivation (Zimmerman, 1986). SRL strategies are behavioral components of the SRL theory. SRL strategies refer to "actions and processes directed at acquiring information or skill that involve agency, purpose, and instrumentality perceptions by learners" (Zimmerman, 1989, p. 329).

Previous research findings showed that SRL strategies predicted perceived effectiveness in online learning environments (Amoozegar, Daud, Mahmud, \& Jalil, 2017; Puzziferro, 2008). For example, the results of a study by Amoozegar et al. (2017) showed that SRL strategies of Malaysian undergraduate students who were taking online courses significantly predicted their satisfaction with the course. While a few studies on MOOCs have examined the effects of SRL strategies on perceived effectiveness, Magen-Nagar and Cohen (2016) found that SRL strategies were positively correlated with the degrees to which high school students evaluated the quality of their academic achievement in a MOOC. However, this research finding was limited to high school students and flipped classroom settings where students watched lecture videos from a MOOC every week and then studied in small groups in the classroom. Considering that people from all over the world with differing backgrounds, including age and education levels, enroll in MOOCs, there is a need to further investigate the effects of SRL strategies on perceived effectiveness in fully online MOOC settings.

Self-efficacy. Self-efficacy is defined as "people's beliefs about their capabilities to produce designated levels of performance that exercise influence over events that affect their lives" (Bandura, 1994, p. 71). Self-efficacy has been identified as a significant predictor of perceived effectiveness in online learning settings (Artino, 2007; Liaw, 2008). For example, the findings of a survey study by Artino (2007) indicated 
that self-efficacy of US Navy sailors in self-paced online courses significantly predicted their perceptions of how well they learned in the courses as well as their satisfaction with the courses. In addition, Liaw (2008) found that Taiwan students' self-efficacy beliefs were a vital factor that influenced their satisfaction with the Blackboard e-learning system. Although self-efficacy has been identified as a factor contributing to perceived effectiveness in online learning settings, there has been a lack of studies examining the influence of self-efficacy on the perceived effectiveness of MOOCs.

Task value. Task value refers to "students' evaluation of the how interesting, how important, and how useful the task is" (Pintrich, Smith, Garcia, \& McKeachie, 1993, p. 11). Task value has been identified as a significant predictor of perceived effectiveness in online learning environments (Artino, 2008; Joo, Lim \& Kim, 2013; Miltiadou, 2001). For example, Artino (2008) found that self-efficacy significantly predicted service academy undergraduate students' satisfaction with self-paced online courses. In addition, Miltiadou (2001) investigated community college students who took an online English course and found task value was a significant predictor of their satisfaction with the courses. Through structural equation modeling, Joo et al. (2013) found direct effects of self-efficacy on satisfaction with online courses offered by an online university in South Korea. Although task value has been identified as a factor contributing to perceived effectiveness in online learning environments, little is known about the predictive power of task value for the perceived effectiveness of MOOCs.

Based on previous studies reviewed above, the present study investigated the influence of successful MOOC learners' SRL strategies, self-efficacy, and task value on perceived effectiveness of a MOOC. This study was framed by the following research questions and research hypotheses:

Research question one: Do successful MOOC learners' SRL strategies, self-efficacy, and task value predict their perceived effectiveness of a MOOC?

$H_{1}$ : Successful MOOC learners' SRL strategies will significantly predict their perceived effectiveness of a MOOC.

$\mathrm{H}_{2}$ : Successful MOOC learners' self-efficacy will significantly predict their perceived effectiveness of a MOOC.

$H_{3}$ : Successful MOOC learners' task value will significantly predict their perceived effectiveness of a MOOC.

Research question two: Which SRL strategies are positively related to successful learners' perceived effectiveness of a MOOC?

\section{Method}

\section{Study Context}

The context of the present study was a MOOC titled Mountain 101 offered by the University of Alberta on the Coursera platform. The course was designed to provide a broad and integrated overview of the mountain 
world. It covered interdisciplinary dimensions of mountain places in Canada and around the world (e.g., physical, biological, and human dimensions). The course was delivered fully online and taught by two instructors. It consisted of 12 lessons with lecture videos, readings, and quizzes. Discussion forums were also provided to allow students to discuss course materials with peers or ask questions of the instructors. It was suggested that students complete one lesson each week. However, they were able to complete all lessons according to their preferred pace. The course was free, but if students wanted to get a certificate of completion, they could pay a small fee. The research team had no affiliation with the MOOC instructors or the Coursera platform institution.

\section{Recruitment and Respondents}

Once Institutional Review Board approval was granted, the researchers asked the MOOC instructors to forward an e-mail that included a survey link with a recruitment message to students who were identified as having completed the Mountain $101 \mathrm{MOOC}$ on the Coursera platform. The e-mail was sent out at the end of October in 2018. Since the MOOC launched in January 2017 and ran until the middle of October 2018, by then a total of 4,333 students had completed the course. The survey was voluntary and no compensation was given to participants.

Of the 4,333 students who received the recruitment e-mail from the MOOC instructors, 353 participated in the survey. As 31 students out of the 353 did not complete the survey, their survey responses were excluded. In addition, 31 outliers were detected and removed to conduct stepwise multiple linear regression analyses. Finally, the responses of the 291 students from 26 countries were analyzed. In terms of age, 13 students were 18 to 25 years of age (4.5\%); 50 students were 26 to 35 years of age (17.2\%); 47 students were 36 to 45 years of age (16.2\%); 44 students were 46 to 55 years of age (15.1\%); 93 students were 56 to 65 years of age (32.0\%); and 44 students were over 66 years of age (15.5\%). Regarding gender, 119 students were male (40.9\%) and 172 students were female (59.1\%).

\section{Instruments}

The revised version of the Self-Regulated Online Learning Questionnaire (SOL-Q-R) developed by Jansen, Van Leeuwen, Janssen, and Kester (2018) was used to measure MOOC learners' SRL strategies in this study. Janssen, Van Leeuwen, Janssen, Kester, and Kalz (2017) developed the initial version of the SOL-Q to measure the SRL strategies of learners in MOOC environments. The revised version of SOL-Q consists of seven subscales: (a) meta-cognitive activities before learning, (b) meta-cognitive activities during learning, (c) meta-cognitive activities after learning, (d) time management, (e) environmental structuring, (f) persistence, and (g) help-seeking (Jansen et al., 2018). The items were rated on a 7-point Likert scale ranging from not at all true of me to very true for me. In this study, the reliability with Cronbach's alpha value was .93.

Seven self-efficacy items from the Motivated Strategies for Learning Questionnaire (MSLQ) (Pintrich, Smith, Garcia, \& McKeachie, 1991) were used to measure MOOC learners' self-efficacy. The items consisted of a seven-point Likert scale ranging from not at all true of me to very true of me. The items were slightly modified to reflect the context of the Mountain 101 MOOC. For example, "I'm confident I can understand the most complex material presented by the instructor in this course" was modified to "I was confident I 
could understand the most complex material presented by the instructor in the Mountain 101 MOOC." The reliability with Cronbach's alpha value was identified as .95.

Six task value items from the MSLQ (Pintrich et al., 1991) were used to measure MOOC learners' task value. The items utilized a seven-point Likert scale ranging from not at all true of me to very true of me. The items were slightly modified to reflect the context of the Mountain 101 MOOC. For example, "I am very interested in the content area of this course" was modified to "I was very interested in the content area of the Mountain 101 MOOC." In this study, the reliability with Cronbach's alpha value was .75.

Three items developed by Peltier et al. (2003) were used to measure MOOC learners' perceived effectiveness. The items consisted of a five-point Likert scale ranging from strongly disagree to strongly agree. As well, the words "this course" were modified to "Mountain 101 MOOC" to better fit the specific MOOC in question. For example, "I would recommend this course to friends/colleagues" was modified to "I would recommend the Mountain 101 MOOC to friends/colleagues." The reliability with Cronbach's alpha value was identified as .75.

The content validity of the revised version of SOL-Q items, self-efficacy items, task value items, and perceived effectiveness items was established through content-related evidence by two professors in the area of educational technology. They reviewed the modified items and assessed the degree to which each one appropriately represented the content domain. Content-related evidence is "validity evidence based on a judgement of the degree to which the items, tasks, or questions on a test adequately represent the construct domain of interest" (Johnson \& Christensen, 2017, p. 380). Judgements of content validity have to be done by experts in the content domain (Johnson \& Christensen, 2017).

\section{Data Analysis}

Survey datasets were analyzed by using the SPSS statistical software program. Stepwise multiple regression was employed to address research questions 1 and 2 . While stepwise multiple regression is appropriate for exploratory studies, hierarchical multiple regression is used when the order of entry for predictor variables is determined based on a theory. Since existing SRL models do not explain contributions of predictor variables to dependant variable, stepwise multiple regression was used. In this study, independent or predictor variables were SRL strategies, self-efficacy, and task value. The dependent variable was perceived effectiveness. All assumptions for multiple linear regression were checked. A violation of homoscedasticity was detected by the Breusch-Pagan test $(p<.05)$ (Breusch \& Pagan, 1979). Therefore, weighted least square (WLS) where "each case is weighted by a function of its variance" (Field, 2013, p. 222) was used to address homoscedasticity.

\section{Results}

\section{The Results of Stepwise Multiple Regression Analysis for Research Question One}

In order to conduct stepwise multiple regression analysis, all assumptions for multiple linear regression were tested. First, the variance inflation factor (VIF), which was lower than 10, showed that multicollinearity does not exist. In addition, the Durbin-Watson test result, which was 2.oo, indicated that 
the assumption of independent errors was met. After WLS estimation was performed, stepwise multiple regression analysis was conducted with an entrance level of 0.05 and an exclusion level of 0.10. Table 1 shows the results of descriptive statistics and Pearson correlation analysis. The results of Pearson correlation analysis indicated that task value was positively correlated with self-efficacy, SRL strategies, and perceived effectiveness. On the other hand, self-efficacy was not positively correlated with SRL strategies, or with perceived effectiveness.

Table 1

Means, Standard Deviations, and Pearson Correlations for Self-Efficacy, Task Value, SRL Strategies, and Perceived Effectiveness

\begin{tabular}{|c|c|c|c|c|c|c|c|}
\hline & Variable & $M$ & $S D$ & 1 & 2 & 3 & 4 \\
\hline 1 & Self-efficacy & 6.07 & .60 & - & $.26^{* *}$ & .05 & .09 \\
\hline 2 & Task value & $5 \cdot 96$ & .65 & $.26^{* *}$ & - & $.34^{* *}$ & $.31^{* * *}$ \\
\hline 3 & SRL strategies & 4.25 & .77 & .05 & $.34^{* *}$ & - & $.23^{* *}$ \\
\hline 4 & Perceived effectiveness & 4.83 & .38 & .09 & $.31^{* * *}$ & $.23^{* * *}$ & - \\
\hline
\end{tabular}

Note. ${ }^{* *} p<.01$.

Table 2 shows the results of stepwise multiple regression analysis. In the first step, SRL strategies were first entered into the regression model. Model 1 was identified as statistically significant with $F(1,289)=36.48$, $p<$.01. It accounted for approximately $11 \%$ of the variance of perceived effectiveness $\left(R^{2}=.11\right.$, adjusted $R^{2}$ $=.11)$. On the second step, task value was added to the model. Model 2 was statistically significant $(F(2$, $288)=31.03, p<.01)$ and accounted for approximately $17 \%$ of the variance of perceived effectiveness $\left(R^{2}\right.$ $=.18$, adjusted $R^{2}=.17$ ). Self-efficacy was excluded in the final model because it did not make a statistically significant addition to the current regression equation. The final model indicated that perceived effectiveness was mainly predicted by SRL strategies, and to a lesser extent by task value. Therefore, hypothesis 1 and 3 are supported, but hypothesis 2 is not supported. 
Table 2

Results of Stepwise Multiple Regression Analysis

\begin{tabular}{|c|c|c|c|c|c|c|}
\hline \multirow{2}{*}{ Variable } & \multicolumn{3}{|c|}{ Model 1} & \multicolumn{3}{|c|}{ Model 2} \\
\hline & B & $S E$ & $\beta$ & B & $S E$ & $\beta$ \\
\hline SRL strategies & .72 & .01 & $.34^{* *}$ & .06 & .01 & $.29^{* *}$ \\
\hline Task value & & & & .07 & .01 & $.26^{* *}$ \\
\hline \multicolumn{7}{|l|}{ Self-efficacy } \\
\hline$R^{2}$ & & & .11 & & & .18 \\
\hline Adjusted $R^{2}$ & & & .11 & & & .17 \\
\hline$F$ & & & $36.48^{*}$ & & & $31.03^{*}$ \\
\hline
\end{tabular}

Note. $\mathrm{B}=$ unstandardized beta; $S E=$ standard error. ${ }^{*} p<.01{ }^{* *} p<.05$.

\section{The Results of Stepwise Multiple Regression Analysis for Research Question Two}

Prior to carrying out stepwise multiple regression, 34 outliers were detected within each SRL strategy variable and removed from data analysis. Then, all assumptions were checked and met. The result of Koenker's test confirmed homoscedasticity ( $\mathrm{p}>$.05). VIF which was lower than 10 showing that there was no multicollinearity. In addition, the Durbin-Watson test result was 2.01 indicating that the residuals were uncorrelated. Stepwise multiple regression analysis was performed with an entrance level of 0.05 and an exclusion level of 0.10. Table 3 presents the results of descriptive statistics and Pearson correlation analysis. As shown in Table 3, there were positive correlations between sub-SRL strategies and perceived effectiveness except between persistence and perceived effectiveness, and between help-seeking and perceived effectiveness. 
Table 3

Means, Standard Deviations, and Pearson Correlations for Sub-SRL Strategies and Perceived Effectiveness

\begin{tabular}{|c|c|c|c|c|c|c|c|c|c|c|c|}
\hline & Variable & $M$ & $S D$ & 1 & 2 & 3 & 4 & 5 & 6 & 7 & 8 \\
\hline 1 & MTBL & 4.59 & 1.85 & - & $.74^{*}$ & $.68^{*}$ & $.42^{*}$ & $.41^{*}$ & $.27^{*}$ & $.17^{*}$ & $.20^{*}$ \\
\hline 2 & MTDL & 4.50 & 1.21 & $.74^{*}$ & - & $.73^{*}$ & $.41^{*}$ & $.31^{*}$ & $.32^{*}$ & $.23^{*}$ & $.21^{*}$ \\
\hline 3 & MTAL & 4.65 & 1.06 & $.68^{*}$ & $.73^{*}$ & - & $.33^{*}$ & $.30^{*}$ & $.22^{*}$ & $.16^{*}$ & $.25^{*}$ \\
\hline 4 & $\mathrm{TM}$ & 4.47 & 0.54 & $.42^{*}$ & $.41^{*}$ & $.33^{*}$ & - & $.21^{*}$ & $.28^{*}$ & .10 & $.15^{* * *}$ \\
\hline 5 & $\mathrm{ES}$ & $5 \cdot 36$ & 1.19 & $.41^{*}$ & $\cdot 31^{*}$ & $.30^{*}$ & $.21^{*}$ & - & $.12^{* *}$ & .06 & $.21^{*}$ \\
\hline 6 & PER & 4.26 & 1.22 & $.27^{*}$ & $\cdot 32^{*}$ & $.22^{*}$ & $.28^{*}$ & $.12^{* * *}$ & - & $.13^{*}$ & .03 \\
\hline 7 & HS & 1.95 & 1.08 & $.17^{*}$ & $.23^{*}$ & $.16^{*}$ & .10 & .06 & $.13^{* *}$ & - & .00 \\
\hline 8 & PEFF & 4.83 & 0.38 & $.20^{*}$ & $.21^{*}$ & $.25^{*}$ & $.15^{* * *}$ & $.21^{*}$ & .03 & .00 & - \\
\hline
\end{tabular}

Note. $\mathrm{MTBL}=$ meta-cognitive activities before learning, $\mathrm{MTDL}=$ meta-cognitive activities during learning, $\mathrm{MTAL}=$ meta-cognitive activities after learning, TM = time management, ES = environmental structuring, PER = persistence, HS $=$ help-seeking, and PEFF $=$ perceived effectiveness. ${ }^{*} p<.01$ and ${ }^{* *} p<.05$.

As shown in Table 4, in the first step, meta-cognitive activity after learning was first added into the regression model. Model 1 was statistically significant $(F(1,255)=24.64, p<.01)$. It accounted for approximately $9 \%$ of the variance of perceived effectiveness $\left(R^{2}=.09\right.$, adjusted $\left.R^{2}=.09\right)$. On the second step, environmental structuring was added to the model. Model 2 was statistically significant $(F(2,254)=$ $18.51, p<.01)$ and accounted for approximately $12 \%$ of the variance of perceived effectiveness $\left(R^{2}=.13\right.$, adjusted $R^{2}=.12$ ). On the third step, time management was entered into the model. The final model was identified as statistically significant $(F(3,253)=13.81, p<.01)$ and accounted for approximately $13 \%$ of the variance of perceived effectiveness $\left(R^{2}=.14\right.$, adjusted $\left.R^{2}=.13\right)$. The final model showed that perceived effectiveness was primarily predicted by meta-cognitive activities after learning, and to a lesser extent by environmental structuring, followed by time management. 
Table 4

Results of Stepwise Multiple Regression Analysis

\begin{tabular}{|c|c|c|c|c|c|c|c|c|c|}
\hline \multirow{2}{*}{ Variable } & \multicolumn{3}{|c|}{ Model 1} & \multicolumn{3}{|c|}{ Model 2} & \multicolumn{3}{|c|}{ Model 3} \\
\hline & B & $S E$ & $\beta$ & B & $S E$ & $\beta$ & B & $S E$ & $\beta$ \\
\hline MTAL & .12 & .02 & $.30^{* *}$ & .10 & .03 & $.24^{* *}$ & .08 & .03 & $.21^{* *}$ \\
\hline ES & & & & .08 & .24 & $.21^{* *}$ & .07 & .02 & $.19^{* *}$ \\
\hline $\mathrm{TM}$ & & & & & & & .11 & .06 & $.12^{* *}$ \\
\hline MTBL & & & & & & & & & \\
\hline MTDL & & & & & & & & & \\
\hline PER & & & & & & & & & \\
\hline HS & & & & & & & & & \\
\hline$R^{2}$ & & & .09 & & & .13 & & & .14 \\
\hline $\begin{array}{l}\text { Adjusted } \\
R^{2}\end{array}$ & & & .09 & & & .12 & & & .13 \\
\hline$F$ & & & $24.64^{*}$ & & & $18.51^{*}$ & & & $13.81^{*}$ \\
\hline
\end{tabular}

Note. $\mathrm{B}=$ unstandardized beta; $S E=$ standard error. ${ }^{*} p<.01$ and ${ }^{* *} p<.05$.

\section{Discussion}

This study investigated the influences of successful MOOC learners' SRL strategies, self-efficacy, and task value on perceived effectiveness of a MOOC. Factors that affect perceived effectiveness have been examined in MOOCs mainly from the perspective of instructors, which has resulted in limited instructional design implications for MOOCs. In addition, the understanding of SRL strategies, self-efficacy, and task value of learners who successfully completed MOOCs is scarce, which has limited our understanding of how to support other learners' SRL based on successful MOOC learners' self-regulation.

\section{Research Question One: Do Successful MOOC Learners' SRL Strategies, Self-Efficacy, and Task Value Predict Their Perceived Effectiveness of a MOOC?}

The results of stepwise multiple regression analysis indicated that successful MOOC learners' perceived effectiveness of the course was significantly predicted by both their use of SRL strategies and the task value of the Mountain 101 MOOC. In model 1 of stepwise multiple regression, SRL strategies were a significant and positive predictor of perceived effectiveness. In the final model where task value was added, SRL strategies significantly predicted perceived effectiveness. These study findings are consistent with previous 
studies on SRL in traditional online learning, showing that SRL strategies and task value significantly predict perceived effectiveness (e.g., Amoozegar et al., 2017; Puzziferro, 2008). In the final model of stepwise multiple regression, task value was also a significant predictor of perceived effectiveness, congruent with previous study findings (Artino, 2008; Miltiadou, 2001). These findings support an assertion that learners' SRL should be also considered in instructional design for effective online learning (Liaw \& Huang, 2013). For example, MOOC instructors should provide an activity where learners set their own goals and make plans for effective time management at the beginning of courses, as suggested in MOOC design guidelines developed by Park, Cha, and Lee (2016). In addition, MOOC instructors should decrease monotony in designing and developing MOOCs as suggested for online learning environments by Chiu and Wang (2008).

On the other hand, successful MOOC learners' self-efficacy was not correlated with the perceived effectiveness of the Mountain 101 MOOC. Furthermore, it was excluded in the final model of stepwise multiple regression, indicating that self-efficacy did not predict perceived effectiveness. This finding is in contrast to previous study findings showing that self-efficacy significantly predicted perceived effectiveness in traditional online learning environments (e.g., Artino, 2007; Liaw, 2008). One of the possible explanations is that the self-efficacy items used in this study might not fit with the context of Mountain 101 MOOC. Although self-efficacy is often domain-specific (Bandura, 1982), self-efficacy items used in this study were general. As the development of self-efficacy has been increasingly emphasized in MOOCs (Hodges, 2016), new self-efficacy items or other methods to correctly measure learners' self-efficacy in different MOOC contexts should be developed and used.

\section{Research Question Two: Which SRL Strategies Are Positively Related to Successful Learners' Perceived Effectiveness of a MOOC?}

The perceived effectiveness of the Mountain 101 MOOC was significantly predicted by successful MOOC learners' meta-cognitive activities after learning. Meta-cognition is positively correlated with academic outcomes as shown in a systematic review on SRL in online higher education learning environments (Broadbent \& Poon, 2015). The effects of meta-cognition in MOOCs have recently been given attention by researchers (e.g., Tsai, Lin, Hong, \& Tai, 2018). The findings of the present study contribute to the body of studies examining meta-cognition in MOOCs as well as shed new light on the role of meta-cognitive activities after learning in a MOOC. It was important for learners who successfully completed the Mountain 101 MOOC to use meta-cognitive strategies after learning. Therefore, MOOC instructors or instructional designers should provide meta-cognitive support for students as it has been emphasized in traditional online learning environments (An \& Cao, 2014). For example, since evaluating thinking process is one of the basic meta-cognitive strategies (Dirkes, 1985), students should be offered prompt questions to allow them to evaluate their learning process right after finishing each module or whole course.

Successful MOOC learners' environmental structuring significantly predicted their perceived effectiveness of the Mountain 101 MOOC. Environment structuring "involves selecting or creating effective settings for learning” (Zimmerman, 1998, p. 78). A few empirical study findings have shown the importance of environment structuring in traditional online learning environments. However, in general, students need to set a dedicated space for studying to succeed in online learning (Pappas, 2015). In addition, online learners are easily distracted because of their personal life activities such as taking care of family (Kerr, 
2011). The findings of the present study showed that learners who successfully completed the Mountain 101 MOOC employed an environment structuring strategy, which significantly predicted their perceived effectiveness. Therefore, as García Espinosa, Tenorio Sepúlveda, and Ramírez Montoya (2015) suggested, MOOC instructors could offer activities where learners can identify the distractions they face while taking MOOCs, and then discuss ways to reduce them in an online forum.

The perceived effectiveness of the course by learners who successfully completed the Mountain 1O1 MOOC was significantly predicted by the learners' use of time management strategies. This result is supported by the importance of time management in MOOC environments. In fact, time management has been identified as one of the most important SRL strategies in MOOCs. For example, Nawrot and Doucet (2014) conducted a survey with 508 MOOC learners and found that poor time management was the main reason for withdrawing from a MOOC. In addition, in Kizilcec, Pérez-Sanagustín, and Maldonado's (2016) survey study, 17 learners who completed a MOOC responded that time management was one of the most important SRL strategies for succeeding in MOOCs. While little has been identified about the effect of time management strategies in MOOC environments, the finding of this study provides empirical evidence of it. MOOC practitioners should support learners' use of time management strategies to help them succeed in MOOCs. For example, as Nawrot and Doucet (2014) proposed, based on learners' behavior and performance datasets from MOOC platforms, MOOC practitioners could predict the amount of time learners will need to complete a specific type of task, rather than a complete unit, and provide suggestions for learners who plan to complete this type of task.

\section{Conclusion}

This study investigated the influence of SRL strategies, self-efficacy, and task value on perceived effectiveness of a course by learners who successfully completed the Mountain 101 MOOC. While SRL strategies and task value significantly predicted successful learners' perceived effectiveness of the MOOC, self-efficacy did not. These study findings provide new insights on instructional design considerations for MOOCs by revealing the importance of learners' use of SRL strategies and task value beliefs. They support Liaw and Huang's (2013) assertation that SRL should be considered in instructional design for effective online courses. In addition, learners' perceptions of interest, importance, and usefulness of the MOOC should be considered when designing MOOCs. In terms of sub-SRL strategies, meta-cognitive activities after learning, environmental structuring, and time management strategies significantly predicted successful MOOC learners' perceived effectiveness of the course. As it has been shown that successful MOOC learners' behaviors positively affected other learners' success (Davis et al., 2016), it is important for MOOC instructors to support their learners' use of these SRL strategies in MOOCs.

There are limitations to this study. First, the data used in the present study only represents the context of the Mountain 101 MOOC. For more generalizable results, future research should investigate other MOOCs addressing the same topic or different topics. In addition, this study relied on data drawn from self-reported questionnaires and used a quantitative method. Although self-reported questionnaires have been widely used in empirical studies to examine SRL in MOOC environments (e.g., Alario-Hoyos, Estévez-Ayres, PérezSanagustín, Kloos, \& Fernández-Panadero, 2017; Morales Chan, Hernandez Rizzardini, Barchino Plata, \& 
Amelio Medina, 2015), future research could benefit from employing qualitative methods to explore more deeply individual learners' SRL strategies, self-efficacy, and task value and their effects on perceived effectiveness of MOOCs. 


\section{References}

Alario-Hoyos, C., Estévez-Ayres, I., Pérez-Sanagustín, M., Kloos, C. D., \& Fernández-Panadero, C. (2017). Understanding learners' motivation and learning strategies in MOOCs. The International Review of Research in Open and Distributed Learning, 18(3), 119-137. https://doi.org/10.19173/irrodl.v18i3.2996

Alraimi, K. M., Zo, H., \& Ciganek, A. P. (2015). Understanding the MOOCs continuance: The role of openness and reputation. Computers \& Education, 8o, 28-38. https://doi.org/10.1016/j.compedu.2014.08.006

Amoozegar, A., Daud, S. M., Mahmud, R., \& Jalil, H. A. (2017). Exploring learner to institutional factors and learner characteristics as a success factor in distance learning. International Journal of Innovation and Research in Educational Sciences, 4(6), 647-656. Retrieved from http://www.ijires.org/administrator/components/com jresearch/files/publications/IJIRES 112 2 FINAL.pdf

An, Y. J., \& Cao, L. (2014). Examining the effects of metacognitive scaffolding on students' design problem solving and metacognitive skills in an online environment. Journal of Online Learning and Teaching, 10(4), 552-568. Retrieved from https://pdfs.semanticscholar.org/48fe/fa6c8f2a676513ff3819f87481ege62a419b.pdf

Artino, A. R. (2007). Online military training: Using a social cognitive view of motivation and selfregulation to understand students' satisfaction, perceived learning, and choice. Quarterly Review of Distance Education, 8(3), 191-202.

Artino, A. R. (2008). Motivational beliefs and perceptions of instructional quality: Predicting satisfaction with online learning. Journal of Computer Assisted Learning, 24(3), 260-270. https://doi.org/10.1111/j.1365-2729.2007.00258.x

Bandura, A. (1982). Self-efficacy mechanism in human agency. American Psychologist, 37, 122-147.

Bandura, A. (1994). Self-efficacy. In V. S. Ramachaudran (Ed.), Encyclopedia of human behavior (pp. 7181). New York, NY: Academic Press.

Bolliger, D. U., \& Halupa, C. (2012). Student perceptions of satisfaction and anxiety in an online doctoral program. Distance Education, 33(1), 81-98. https://doi.org/10.1080/01587919.2012.667961

Breusch, T. S., \& Pagan, A. R. (1979). A simple test for heteroscedasticity and random coefficient variation. Econometrica: Journal of the Econometric Society, 47(5), 1287-1294. https://doi.org/10.2307/1911963

Broadbent, J., \& Poon, W. L. (2015). Self-regulated learning strategies \& academic achievement in online higher education learning environments: A systematic review. The Internet and Higher Education, 27, 1-13. https://doi.org/10.1016/j.iheduc.2015.04.007 
Chiu, C. M., \& Wang, E. T. (2008). Understanding Web-based learning continuance intention: The role of subjective task value. Information \& Management, 45(3), 194-201.

https://doi.org/10.1016/j.im.2008.02.003

Cho, M. H., \& Cho, Y. (2017). Self-regulation in three types of online interaction: A scale development. Distance Education, 38(1), 70-83. https://doi.org/10.1080/01587919.2017.1299563

Davis, D. J., Chen, G., Jivet, I., Hauff, C., \& Houben, G. (2016, April). Encouraging metacognition and self-regulation in MOOCs through increased learner feedback. In CEUR Workshop Proceedings: Vol. 1596 (pp. 17-22). Retrieved from http://ceur-ws.org/Vol-1596/paper3.pdf

Dick, W. \& Carey, L. M. (1978). The systematic design of instruction. New York, NY: HarperCollins.

Dirkes, M. A. (1985). Metacognition: Students in charge of their thinking. Roeper Review, 8(2), 96-100. https://doi.org/10.1080/02783198509552944

Field, A. (2013). Discovering statistics using IBM SPSS statistics (4th ed.). London, England: SAGE.

García Espinosa, B. J., Tenorio Sepúlveda, G. C., \& Ramírez Montoya, M. S. (2015). Self-motivation challenges for student involvement in the open educational movement with MOOC. Revista De Universidad Y Sociedad Del Conocimiento, 12(1), 91-103. https://doi.org/10.7238/rusc.v12i1.2185

Hodges, C. (2016, April). The development of learner self-efficacy in MOOCs. In Proceedings of Global Learn-Global Conference on Learning and Technology (pp. 517-522). Limerick, Ireland. Retrieved from https://www.learntechlib.org/p/172763

Hone, K. S., \& El Said, G. R. (2016). Exploring the factors affecting MOOC retention: A survey study. Computers \& Education, 98, 157-168. https://doi.org/10.1016/j.compedu.2016.03.016

Hood, N., Littlejohn, A., \& Milligan, C. (2015). Context counts: How learners' contexts influence learning in a MOOC. Computers \& Education, 91, 83-91. https://doi.org/10.1016/j.compedu.2015.10.019

Jansen, R. S., Van Leeuwen, A., Janssen, J., \& Kester, L. (2018). Validation of the Revised Self-regulated Online Learning Questionnaire. In V. Pammer-Schindler, M. Pérez-Sanagustín, H. Drachsler, R.Elferink, \& M. Scheffel (Eds.), Proceedings of the European Conference on Technology Enhanced Learning (pp. 116-121). Cham, Switzerland: Springer.

Jansen, R. S., Van Leeuwen, A., Janssen, J., Kester, L., \& Kalz, M. (2017). Validation of the self-regulated online learning questionnaire. Journal of Computing in Higher Education, 29(1), 6-27. https://doi.org/10.1007/s12528-016-9125-X

Johnson, B., \& Christensen, L. (2017). Educational research: Quantitative, qualitative, and mixed approaches (6th ed.). Thousand Oaks, CA: Sage. 
Joo, Y. J., Lim, K. Y., \& Kim, J. (2013). Locus of control, self-efficacy, and task value as predictors of learning outcome in an online university context. Computers \& Education, 62, 149-158. https://doi.org/10.1016/j.compedu.2012.10.027

Jung, E., Kim, D., Yoon, M., Park, S., \& Oakley, B. (2019). The influence of instructional design on learner control, sense of achievement, and perceived effectiveness in a supersize MOOC course. Computers \& Education, 128, 377-388. https://doi.org/10.1016/j.compedu.2018.10.001

Kang, M., \& Im, T. (2013). Factors of learner-instructor interaction which predict perceived learning outcomes in online learning environment. Journal of Computer Assisted Learning, 29(3), 292301. https://doi.org/10.1111/jcal.12005

Kerr, S. (2011). Tips, tools, and techniques for teaching in the online high school classroom. TechTrends, $55(1), 28-31$.

Kizilcec, R. F., Pérez-Sanagustín, M., \& Maldonado, J. J. (2016, April). Recommending self-regulated learning strategies does not improve performance in a MOOC. Paper presented at Learning@Scale 2016, Edinburgh, Scotland. https://doi.org/10.1145/2876034.2893378

Lee, D., Watson, S. L., \& Watson, W. R. (2019). Systematic literature review on self-regulated learning in massive open online courses. Australasian Journal of Educational Technology, 35(1), 28-41. https://doi.org/10.14742/ajet.3749

Liaw, S. S. (2008). Investigating students' perceived satisfaction, behavioral intention, and effectiveness of e-learning: A case study of the Blackboard system. Computers \& Education, 51(2), 864-873. https://doi.org/10.1016/j.compedu.2007.09.005

Liaw, S. S., \& Huang, H. M. (2013). Perceived satisfaction, perceived usefulness and interactive learning environments as predictors to self-regulation in e-learning environments. Computers \& Education, 6o(1), 14-24. https://doi.org/10.1016/j.compedu.2012.07.015

Magen-Nagar, N., \& Cohen, L. (2016). Learning strategies as a mediator for motivation and a sense of achievement among students who study in MOOCs. Education and Information Technologies, 22(3), 1-20. https://doi.org/10.1007/s10639-016-9492-y

Milligan, C., \& Littlejohn, A. (2016). How health professionals regulate their learning in massive open online courses. The Internet and Higher Education, 31, 113-121. https://doi.org/10.1016/j.iheduc.2016.07.005

Miltiadou, M. (2001). Motivational constructs as predictors of success in the online classroom. Dissertation Abstracts International, 61(9-A), 3527.

Morales Chan, M., Hernandez Rizzardini, R., Barchino Plata, R., \& Amelio Medina, J. (2015). MOOC using cloud-based tools: A study of motivation and learning strategies in Latin America. 
International Journal of Engineering Education, 31(3), 901-911. Retrieved from http://www.ijee.ie/latestissues/Vol31-3/22 ijee3046ns.pdf

Nawrot, I., \& Doucet, A. (2014, April). Building engagement for MOOC students: Introducing support for time management on online learning platforms. Paper presented at the 23rd International World Wide Web Conference, Seoul, South Korea. https://doi.org/10.1145/2567948.2580054

Pappas, C. (2015, June). Getting the most out of your eLearning course: 10 study tips for online learners. eLearning Industry. Retrieved from https://elearningindustry.com/10-study-tips-for-onlinelearners-getting-the-most-out-of-your-elearning-course

Park, T. J., Cha, H. J., \& Lee, G. Y. (2016). A study on design guidelines of learning analytics to facilitate self-regulated learning in MOOCs. Educational Technology International, 17(1), 117-150. Retrieved from http://kset.or.kr/eti ojs/index.php/instruction/article/viewFile/61/pdf 19

Peltier, J. W., Drago, W., \& Schibrowsky, J. A. (2003). Virtual communities and the assessment of online marketing education. Journal of Marketing Education, 25(3), 260-276. https://doi.org/10.1177/0273475303257762

Peterson, C. (2003). Bringing ADDIE to life: Instructional design at its best. Journal of Educational Multimedia and Hypermedia, 12(3), 227-241. Retrieved from https://www.learntechlib.org/primary/p/2074/

Pintrich, P. R., Smith, D. A. F., Garcia, T., \& McKeachie, W. J. (1991). A manual for the use of the Motivated Strategies for Learning Questionnaire (MSLQ). Ann Arbor, MI: The University of Michigan. https://doi.org/10.1037/0022-0663.82.1.33

Pintrich, P. R., Smith, D. A., Garcia, T., \& McKeachie, W. J. (1993). Reliability and predictive validity of the Motivated Strategies for Learning Questionnaire (MSLQ). Educational and Psychological Measurement, 53(3), 801-813. https://doi.org/10.1177/0013164493053003024

Puzziferro, M. (2008). Online technologies self-efficacy and self-regulated learning as predictors of final grade and satisfaction in college-level online courses. The American Journal of Distance Education, 22(2), 72-89. https://doi.org/10.1080/08923640802039024

Sujatha, R., \& Kavitha, D. (2018). Learner retention in MOOC environment: Analyzing the role of motivation, self-efficacy and perceived effectiveness. International Journal of Education and Development Using Information and Communication Technology, 14(2), 62-74. Retrieved from http://ijedict.dec.uwi.edu//viewissue.php?id=51

Tsai, Y. H., Lin, C. H., Hong, J. C., \& Tai, K. H. (2018). The effects of metacognition on online learning interest and continuance to learn with MOOCs. Computers \& Education, 121, 18-29. https://doi.org/10.1016/j.compedu.2018.02.011 
Venkatesh, V., Croteau, A. M., \& Rabah, J. (2014, January). Perceptions of effectiveness of instructional uses of technology in higher education in an era of Web 2.0. In 2014 47th Hawaii International Conference on System Sciences (pp. 110-119). IEEE. https://doi.org/10.1109/HICSS.2014.22

Zimmerman, B. J. (1986). Becoming a self-regulated learner: Which are the key subprocesses?. Contemporary Educational Psychology, 11(4), 307-313. https://doi.org/10.1016/0361476X(86)90027-5

Zimmerman, B. J. (1989). A social cognitive view of self-regulated academic learning. Journal of Educational Psychology, 81(3), 329-339. https://doi.org/10.1037/0022-0663.81.3.329

Zimmerman, B. J. (1998). Academic studying and the development of personal skill: A self-regulatory perspective. Educational Psychologist, 33(2/3), 73-86.

Zimmerman, B. J. (2000). Attaining self-regulation: A social cognitive perspective. In M. Boekaerts, P. Pintrich, \& M. Zeidner (Eds.), Handbook of self-regulation (pp. 13-39). San Diego, CA: Academic Press.

\section{Athabasca} University

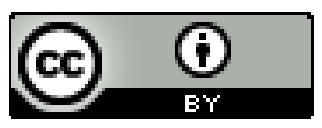

